\title{
A comparison of breastfeeding among Han, Uygur and other ethnic groups in Xinjiang, PR China Fenglian $\mathrm{Xu}^{1}$, Colin Binns*2, Guli Nazi ${ }^{3}$, Lin Shi ${ }^{4}$, Yun Zhao ${ }^{2}$ and Andy Lee ${ }^{2}$
} Address: ${ }^{1}$ Medical College, Shihezi University; Xinjiang, 832002, PR China, ${ }^{2}$ School of Public Health, Curtin University of Technology, 6845,
Western Australia, ${ }^{3}$ Yumin County Hospital, Xinjiang, 834601, PR China and ${ }^{4}$ Manas County Hospital, Xinjiang, 832000, PR China

Email: FenglianXu - f.xu@exchange.curtin.edu.au; Colin Binns* - c.binns@curtin.edu.au; Guli Nazi - fenglianxu@yahoo.com.cn; Lin Shi - xufenglian@shzu.edu.cn; Yun Zhao - y.zhao@curtin.edu.au; Andy Lee - andy.lee@curtin.edu.au

* Corresponding author

Published: 27 July 2006

BMC Public Health 2006, 6:196 doi:10.1 I86/147|-2458-6-196
Received: 09 March 2006

Accepted: 27 July 2006

This article is available from: http://www.biomedcentral.com/I47I-2458/6/196

(c) 2006 Xu et al; licensee BioMed Central Ltd.

This is an Open Access article distributed under the terms of the Creative Commons Attribution License (http://creativecommons.org/licenses/by/2.0), which permits unrestricted use, distribution, and reproduction in any medium, provided the original work is properly cited.

\begin{abstract}
Background: Breastfeeding is an important factor in infant health and there have been no previous studies of breastfeeding practices in the different ethnic groups of this region of China. We aimed to compare breastfeeding rates and duration between Han, Uygur and other ethnic groups living in Xinjiang, PR China.
\end{abstract}

Methods: A longitudinal study of infant feeding practices was undertaken using a sample that included different ethnic groups. Mothers were randomly recruited and interviewed in hospitals and after discharge were contacted in person or by telephone at approximately monthly intervals to obtain details of infant feeding practices. Setting: Xinjiang Uygur Autonomous Region, PR China. Subjects: A total of 1219 mothers (578 Han, 360 Uygur and 28I 'other minority' mothers) who delivered babies during 2003 and 2004 were interviewed in five hospitals or institutes located in both urban and rural areas.

Results: 'Any breastfeeding' rates in Han, Uygur and 'other minority' groups at discharge were 88.5 $\%, 94.3 \%$ and $97.1 \%$ respectively, and at six months $76.7 \%, 54.7 \%$ and $87.6 \%$ respectively. While 'exclusive breastfeeding' rates in the Han, Uygur and 'other minority' groups at discharge were 78.0 $\%, 34.5 \%$ and $83.1 \%$ respectively, at six months they had fallen to $4.8 \%, 0.4 \%$ and $16.8 \%$ respectively. The median duration of 'Exclusive breastfeeding' of Han, Uygur and 'other minority' babies were I.5, 0.1 and 2.5 months respectively. The Uygur babies were least likely to be 'exclusive breastfed'.

Conclusion: Uygur babies were least likely to be 'exclusive breastfed' and continued to 'any breastfeed' at six month. The 'any breastfeeding' rates in the Han group were lower in the first four months. An education program focused on breastfeeding continuation and exclusive breastfeeding is necessary in Xinjiang, especially for Uygur and Han ethnic groups.

\section{Background}

Breastmilk provides the basis for the best nutrition for infants and brings health and development benefits to both babies and mothers $[1,2]$. 'Exclusive breastfeeding' for the first six months of life and continued breastfeeding up to two years of age or beyond are recommended by World Health Organization (WHO) [3]. 
Over the past forty years, China has experienced considerable changes in breastfeeding practices. After the emergence of modern China in the 1950's and 1960's, 'ever breastfed' rates in both urban and rural areas were over $80 \%$. But during the 1970 's, the rates started to decline considerably, especially in larger cities, because the availability and use of breastmilk substitutes became widespread and mothers went to work. For example, the 'ever breastfed' rate in the urban areas of China was $42.7 \%$ in 1975 and decreased to $33.6 \%$ in 1985 [4-6]. While the 'ever breastfeeding' rate in a rural area near Shanghai was $80 \%$ in early 1980 's it had fallen to $44.1 \%$ by the early 1990 's [7]. While the trends towards declining breastfeeding were similar in urban and rural areas, however the decline happened in urban areas a few years earlier and the rates in cities were relatively lower.

To address the decline in breastfeeding, the Chinese government set a national target of an 'exclusive breastfeeding' rate at four months of $80 \%$ by 2000 in the Chinese Children's Development Plan in 1990's [8]. As a result there were many efforts to promote breastfeeding and the breastfeeding rate in China started to increase in 1990's [9]. The breastfeeding initiation rate in Tianjin, one of the larger cites in China, was $55 \%$ in 1985 , rising to $85 \%$ in 1991 and 95\% in 1992 [9]. In a cohort study undertaken in 1997 in the city of Wuhan the 'any breastfeeding' rate was $95 \%$ at one month and $83 \%$ at four months; while the 'exclusive breastfeeding' rate was $88 \%$ at one month and $56 \%$ at four months respectively [10]. The mean duration of 'any breastfeeding', in a cross-sectional survey in 2002, was 6.3 months in Guangdong province, 7.7 months in Beijing, 8.2 months in Zhejiang province, 9.8 months in Hubei province and 12.3 months in Shandong province [11]. The longest breastfeeding mean duration report from China is in Tibet where it was 14.2 months in 1999 [12]. The general pattern in China is that the less developed areas had a relatively longer breastfeeding duration.

China is the most populous country in the world and with 56 ethnic groups. The largest group, the Han ethnic, make up over $92 \%$ of China's population. The remaining 55 ethnic groups are collectively called minorities,

The Xinjiang Uygur Autonomous Region (Xinjiang AR) in North-western China borders eight countries: Russia, Kazakhstan, Kirghizastan, Tajikistan, Pakistan, Mongolia, India and Afghanistan. There are more than 13 ethnic groups living in this area. Among them, the Uygur people account for $46 \%$, Han $40 \%$ and Kazakh $7 \%$. The population of Xinjiang had reached 19.6 million by the end of 2004. The average birth rate was 16 per thousand and death rate 5.1 per thousand.
The cultural factors that influence breastfeeding practices are acknowledged in the literature and have been widely reviewed [13-15]. A cross-sectional study undertaken in the Han ethnic population in Shihezi, Xinjiang in 19941996 found a breastfeeding rate of 34\% at four month [16]. This was well below Chinese and international targets. However no studies have been undertaken on the breastfeeding rates in the minority groups in the province. The comparison between ethnic groups is needed to provide evidence to identify whether specific breastfeeding interventions are needed. The objective of this study was to compare breastfeeding rates and duration between Han ethnic Uygur and 'other minority' groups in Xinjiang, PR China through the first six months after birth.

\section{Methods}

A longitudinal cohort study of breastfeeding practices was undertaken in the Xinjiang Uygur Autonomous Region, PR China. Mothers who delivered babies during 2003 and 2004 were interviewed while in hospital and were invited to participate in the study. The mothers were assured that all of the personal data collected would be kept confidential. After their return home mothers were contacted in person or by telephone at approximately monthly intervals (at $0.5,1.5,2.5,3.5,4.5$ and 6 months respectively) and asked to complete a structured questionnaire to obtain details of breastfeeding practices.

A total of 1256 mothers were recruited from five hospitals and institutes located in urban areas(Shihezi People's Hospital, Shihezi Maternal and Child Health Care Institute, Urumqi Maternal and Child Health Care Institute) and rural areas (Chabuchaer Maternal and Child Health Care Institute and Yumin County Hospital) of the province. These hospitals and institutes covered majority of mothers who delivered babies in the cities and suburbs. About 70\% mothers in Shihezi city and suburb delivered babies in Shihezi People's Hospital (about 50\%) and Shihezi Maternal and Child Health Care Institute(about $20 \%$ ). More than half Uygur babies in Urumqi were born in Urumqi Maternal and Child Health Care Institute. More than 50\% babies in Chabuchaer and more than $60 \%$ in Yumin were born in Chabuchaer Maternal and Child Health Care Institute and Yumin County Hospital respectively. Maternal and Child Health Care Institutes in this study were woman's hospitals and also child health care centres. In Shihezi People's Hospital, mothers were recruited every second days due to due to staffing constraints. In other hospitals, all mothers were invited to the study and 97\% (1219) agree to participate. Urumqi is the capital city of Xinjiang where the Uygur ethnic group is in the majority, while Shihezi is a predominantly Han ethnic area. Chabuchaer and Yumin counties have a larger concentration of Kazakh people and other minorities. 
The majority of participants, including the minority groups, could read and speak Chinese (Mandarin). The questionnaire was originally prepared in Mandarin, and was also translated into the Uygur language, which can also be understood by Kazakh mothers. For those who could not read Chinese, trained nurses, who were fluent in the ethnic languages, were available to help them complete the questionnaires. For all minority mothers, follow up calls and visits were made in their own ethnic languages by nurses from their own ethnic group.

The questionnaire was based on those developed by Scott, Binns and Duong that have been extensively used in breastfeeding cohort studies in Australia, Vietnam and Kenya [17-22]. The questionnaires were designed to identify the feeding method and to collect information on factors associated with breastfeeding. After translation the questionnaires were tested in focus groups to ensure cultural appropriateness.

The project was approved by the Xinjiang local research authorities (Shihezi University, Urumqi Science Research Committee) and the Human Research Ethics Committee of Curtin University, Australia. Mothers who agreed to participate in the study signed the consent page in front of the questionnaire and were informed of their rights to withdraw from the follow up process at anytime without prejudice.

The sample size needed was calculated to be 860 to give a difference of eight percentage points in breastfeeding rates between the Han and Uygur groups at six months. (confidence $95 \%$, power $80 \%$ ), assuming the breastfeeding rate to be $75 \%$ in the Han Chinese. Additional numbers were included because of the other ethnic groups in the sample. All data analyses were carried out using the Statistical Package for Social Science (SPSS), release 12.0 (SPSS Inc., Chicago, IL, USA). Descriptive statistics and cross tabulations were generated for demographic variables, life tables were used for breastfeeding rates and Kaplan-Meier model was used to calculate mean of 'exclusive breastfeeding' and 'full breastfeeding' duration and assessed the differences in different ethnic groups. 'Significant' means $\mathrm{p}$ value less than 0.05 .

The definitions of breastfeeding used in this paper are: [23-25]:

'Any breastfeeding': The child has received breastmilk (direct from the breast or expressed) with or without other drink, formula or other infant food.

'Exclusive breastfeeding': Breastfeeding while giving no other food or liquid, not even water, with the exception of drops or syrups consisting of vitamins, mineral supplements or medicine.

'Predominant breastfeeding': In addition to breastmilk the infant may receive small amounts of culturally valued supplement - water, water-based drinks, fruit juice, and ritualistic fluids.

'Full breastfeeding' includes 'exclusive breastfeeding' and 'predominant breastfeeding'.

\section{Results}

The details of the sample and the distribution of the major demographic variables are shown in Table 1 . The sample (1219) as recruited included 47\% (578) Han, 30\% (360) Uygur, 23\% (281) other minorities.

Almost all of the mothers (1118) in the study were married, with eight separated and one widowed. The mean durations of hospital stay in days were 6.5 days (standard deviation 2.9) for Han Chinese, 6.1 days (SD 1.8) for Uygur and 6.4 days (SD 3.8) for the other ethnic groups. None of these results were significantly different from each other at the $\mathrm{p}<0.05$ level.

The breastfeeding rates were calculated by life table analysis and are detailed in Table 2 . The breastfeeding rates on discharge were $89 \%$ in Han, 94\% in Uygur and 97\% in other ethnic groups and by six months these had declined to $77 \%, 55 \%$ and $88 \%$ respectively.

Inevitably in cohort study some mothers were lost to follow-up (Table 2). The percentage of mothers lost to follow-up at $0.5,1.5,2.53 .5,4.5$ and 6 months were $6 \%$, $7 \%, 9 \%, 12 \%, 13 \%$ and $21 \%$ respectively, that is $79 \%$ of mothers were followed to six months. This represents a response for $87.4 \%$ of the 'person-months' in the study.

Figure 1 shows the 'any breastfeeding' and 'exclusive breastfeeding' rates by months for the different ethnic groups. Uygur babies were least likely to be 'exclusive breastfed' while the 'other minority' group had the highest 'any breastfeeding' and 'exclusive' breastfeeding rates.

Table 3 showed the duration of 'exclusive breastfeeding' and 'full breastfeeding' among ethnic groups. The overall 'exclusive breastfeeding' median was 0.5 month and 'full breastfeeding' median 2.5 months.

The censored rate at six months of 'exclusive breastfeeding' in Uygur, Han and other ethnics were 1.4\%, $14.0 \%$ and $27.8 \%$ respectively, 'full breastfeeding' 9.7\%, $18.9 \%$ and $34.2 \%$ respectively, and 'any breastfeeding' $72.5 \%$, $81.0 \%$ and $91.8 \%$ respectively. Censored cases refer to 
Table I: Demographic Details of Han, Uygur and 'Other Minority' Groups in the Sample from Xinjiang, PR China, $2003-2004$ (n = 1219)

\begin{tabular}{|c|c|c|c|c|c|c|c|c|c|}
\hline \multirow[t]{2}{*}{ Variable } & \multirow[t]{2}{*}{ Value } & \multicolumn{2}{|c|}{ Han } & \multicolumn{2}{|c|}{ Uygur } & \multicolumn{2}{|c|}{ Others } & \multicolumn{2}{|c|}{ Total } \\
\hline & & $\mathrm{n}$ & $\%$ & $\mathrm{n}$ & $\%$ & $\mathrm{n}$ & $\%$ & $\mathrm{n}$ & $\%$ \\
\hline \multirow[t]{3}{*}{ Place* } & Urban Area & 490 & 84.8 & 334 & 92.8 & 85 & 30.2 & 909 & 74.6 \\
\hline & Rural Area & 88 & 15.2 & 26 & 7.2 & 196 & 69.8 & 310 & 25.4 \\
\hline & Missing & 0 & & 0 & & 0 & & 0 & \\
\hline \multirow[t]{3}{*}{ Gestation Age* (weeks) } & $<37$ & 10 & 2.1 & 21 & 7.8 & 8 & 3.6 & 39 & 4.1 \\
\hline & $37+$ & 456 & 97.9 & 248 & 92.2 & 213 & 96.4 & 917 & 95.9 \\
\hline & Missing & 112 & & 91 & & 60 & & 263 & \\
\hline \multirow[t]{4}{*}{ Birth Weight* } & $<2500 \mathrm{~g}$ & 12 & 2.2 & 21 & 6.1 & 4 & 1.5 & 37 & 3.2 \\
\hline & $2500-3999 \mathrm{~g}$ & 496 & 88.9 & 285 & 82.4 & 238 & 90.2 & 1019 & 87.2 \\
\hline & $4000 \mathrm{~g}+$ & 50 & 9 & 40 & 11.6 & 22 & 8.3 & 112 & 9.6 \\
\hline & Missing & 20 & & 14 & & 17 & & 51 & \\
\hline \multirow[t]{3}{*}{ Delivery Method* } & Vaginal Delivery & 243 & 45.2 & 173 & 50.4 & 186 & 72.1 & 602 & 52.9 \\
\hline & Caesarean & 295 & 54.8 & 170 & 49.6 & 72 & 27.9 & 537 & 47.1 \\
\hline & Missing & 40 & & 17 & & 23 & & 80 & \\
\hline \multirow[t]{3}{*}{ Birth Order* } & 1 & 456 & 87.7 & 265 & 77.5 & 203 & 77.8 & 924 & 82.3 \\
\hline & $2+$ & 64 & 12.3 & 77 & 22.5 & 58 & 22.2 & 199 & 17.7 \\
\hline & Missing & 58 & & 18 & & 20 & & 96 & \\
\hline \multirow[t]{3}{*}{ Baby's Gender } & Male & 287 & 51.2 & 191 & 54.3 & 138 & 52.3 & 616 & 52.3 \\
\hline & Female & 274 & 48.8 & 161 & 45.7 & 126 & 47.7 & 561 & 47.7 \\
\hline & Missing & 17 & & 8 & & 17 & & 42 & \\
\hline \multirow[t]{7}{*}{ Maternal Job* } & House Wife & 191 & 35.6 & 169 & 49.1 & 140 & 53.2 & 500 & 43.7 \\
\hline & Sales & 119 & 22.2 & 15 & 4.4 & 21 & 8 & 155 & 13.5 \\
\hline & Worker & 76 & 14.2 & 37 & 10.8 & 6 & 2.3 & 119 & 10.4 \\
\hline & Farmer & 54 & 10.1 & 8 & 2.3 & 33 & 12.5 & 95 & 8.3 \\
\hline & Office Worker & 77 & 14.3 & 111 & 32.3 & 61 & 23.2 & 249 & 21.8 \\
\hline & Others & 20 & 3.7 & 4 & 1.2 & 2 & 0.8 & 26 & 2.3 \\
\hline & Missing & 41 & & 16 & & 18 & & 75 & \\
\hline \multirow[t]{5}{*}{ Maternal Age* (years) } & $<25$ & 67 & 13 & 64 & 19.2 & 53 & 21 & 184 & 16.7 \\
\hline & $25-29$ & 260 & 50.4 & 157 & 47.1 & 127 & 50.4 & 544 & 49.4 \\
\hline & $30-34$ & 160 & 31 & 85 & 25.5 & 62 & 24.6 & 307 & 27.9 \\
\hline & $35+$ & 29 & 5.6 & 27 & 8.1 & 10 & 4 & 66 & 6 \\
\hline & Missing & 62 & & 27 & & 29 & & 118 & \\
\hline \multirow[t]{4}{*}{ Maternal Education* (years) } & $<9$ & 198 & 37.8 & 133 & 38.8 & 145 & 53.9 & 476 & 41.9 \\
\hline & $10-12$ & 166 & 31.7 & 74 & 21.6 & 65 & 24.2 & 305 & 26.8 \\
\hline & $13+$ & 160 & 30.5 & 136 & 39.7 & 59 & 21.9 & 355 & 31.3 \\
\hline & Missing & 54 & & 17 & & 12 & & 83 & \\
\hline \multirow[t]{4}{*}{ Family Annual Income* (RMB) } & $<10000$ & 114 & 28.1 & 79 & 27.8 & 116 & 49.6 & 309 & 33.5 \\
\hline & $10000-19999$ & $17 \mid$ & 42.2 & 113 & 39.8 & 72 & 30.8 & 356 & 38.6 \\
\hline & $20000+$ & 120 & 29.6 & 92 & 32.4 & 46 & 19.7 & 258 & 28 \\
\hline & Missing & 173 & & 76 & & 47 & & 296 & \\
\hline
\end{tabular}


Table I: Demographic Details of Han, Uygur and 'Other Minority' Groups in the Sample from Xinjiang, PR China, 2003-2004 (n = 1219) (Continued)

\begin{tabular}{|c|c|c|c|c|c|c|c|c|c|}
\hline \multirow[t]{5}{*}{ Family Members* } & 3 & 383 & 74.4 & 213 & 64 & 136 & 51.5 & 732 & 65.8 \\
\hline & 4 & 67 & 13 & 93 & 27.9 & 49 & 18.6 & 209 & 18.8 \\
\hline & 5 & 49 & 9.5 & 20 & 6 & 55 & 20.8 & 124 & 11.2 \\
\hline & $6+$ & 16 & 3.1 & 7 & 2.1 & 24 & 9.1 & 47 & 4.2 \\
\hline & Missing & 63 & & 27 & & 17 & & 107 & \\
\hline \multirow[t]{3}{*}{ Paternal smoking } & No & 164 & 33.7 & 118 & 34.7 & 101 & 38.5 & 383 & 35.2 \\
\hline & Yes & 322 & 66.3 & 222 & 65.3 & 161 & 61.5 & 705 & 64.8 \\
\hline & Missing & 92 & & 20 & & 19 & & $13 \mid$ & \\
\hline
\end{tabular}

Notes:

I. The 'other ethnic' group $(n=281)$ included 199 were Kazakh, 56 were Xibe and 26 Hui babies.

2. 100 Renami (RMB or CNY) is the equivalent of 12.5016 USD, 9.91 190 EURO or 6.85308 GBP (Date of conversion 27 June 2006 )

3. There were significant differences in all of the groups marked $*(P<0.01)$

those still breastfeeding or who had been lost to follow-up at six months.

Log-rank tests were run to determine if the duration of 'exclusive breastfeeding' and ' full breastfeeding' differ significantly between pairs of the ethnic groups, namely Uygur, Han and 'other minority' group. There were significant differences in the durations of 'exclusive breastfeeding' between the pairs among the ethnic groups. The 'other minority' group had the longest duration of 'exclu- sive breastfeeding', Uygur the lowest and Han in the middle $(\mathrm{p}<0.01)$. The same trend was in 'full breastfeeding' rate $(\mathrm{p}<0.01)$. The 'any breastfeeding' median duration was greater than six months in all ethnic groups. As follow-up in this study was terminated at six months, the maximum duration of breastfeeding could not be determined.

Uygur babies had the shortest 'exclusive and full breastfeeding' duration, the 'other minority' babies the longest

Table 2: Breastfeeding Rate (\%) in Han Ethnic, Uygur and 'Other Minority' Groups, Xinjiang, PR China, 2003-2004

\begin{tabular}{|c|c|c|c|c|c|}
\hline Ethnic & Month & $\mathrm{n}$ & Exclusive breastfeeding & Full breastfeeding & Any Breastfeeding \\
\hline \multirow[t]{7}{*}{ Han } & $0^{*}$ & 578 & 78.0 & 83.7 & 88.5 \\
\hline & 0.5 & 534 & 61.0 & 71.7 & 87.2 \\
\hline & 1.5 & 530 & 33.9 & 60.2 & 85.6 \\
\hline & 2.5 & 523 & 29.4 & 55.1 & 84.5 \\
\hline & 3.5 & 516 & 24.0 & 43.9 & 83.1 \\
\hline & 4.5 & 502 & 10.9 & 14.8 & 82.0 \\
\hline & 6 & 472 & 4.8 & 5.8 & 76.7 \\
\hline \multirow[t]{7}{*}{ Uygur } & $0^{*}$ & 360 & 34.5 & 90.3 & 94.3 \\
\hline & 0.5 & 341 & 12.6 & 47.2 & 93.4 \\
\hline & 1.5 & 336 & 5.6 & 35.3 & 91.9 \\
\hline & 2.5 & 317 & 4.5 & 22.1 & 90.0 \\
\hline & 3.5 & 305 & 3.7 & 11.2 & 88.6 \\
\hline & 4.5 & 302 & 1.9 & 3.4 & 84.8 \\
\hline & 6 & 260 & 0.4 & I.I & 54.7 \\
\hline \multirow[t]{7}{*}{ Others } & $0^{*}$ & 281 & 83.1 & 95.0 & 97.1 \\
\hline & 0.5 & 272 & 65.9 & 79.9 & 96.7 \\
\hline & 1.5 & 270 & 54.1 & 72.1 & 96.0 \\
\hline & 2.5 & 265 & 46.2 & 61.5 & 96.0 \\
\hline & 3.5 & 254 & 42.4 & 51.7 & 95.6 \\
\hline & 4.5 & 251 & 31.9 & 37.9 & 95.2 \\
\hline & 6 & 232 & 16.8 & 21.3 & 87.6 \\
\hline
\end{tabular}

0 month refers to the time at discharge from hospital, which generally in one week postpartum.

The 'other ethnic' group $(n=28 I)$ included 199 were Kazakh, 56 were Xibe and 26 Hui babies. 


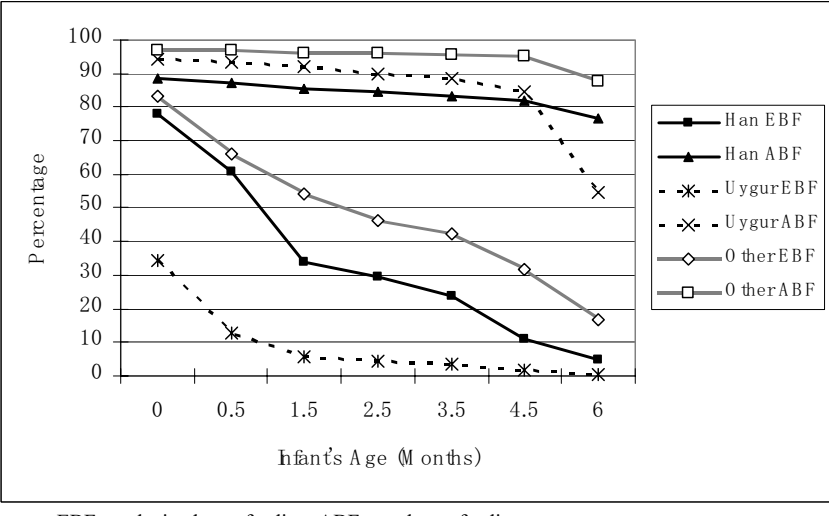

EBF: exclusive breastfeeding. ABF: any breastfeeding

\section{Figure I}

Breastfeeding Rates(\%) in Han Ethnic, Uygur and 'Other Minority' Groups, Xinjiang, PR China, 2003-2004.

and Han babies in the middle of the three groups. By four months of age, $66 \%$ of all infants had been commenced on solid foods. The percentage in Han, Uygur and 'other minority' groups were $71 \%, 85 \%$ and $34 \%$ respectively. At six months, the overall percentage was $78 \%$, including $85 \%$ in the Han group, $91 \%$ in Uygur and $48 \%$ in the 'other minority' group. The differences between the groups were significant.

The factors likely to be associated with 'any breastfeeding' to six months were entered into Cox Regression model and are detailed in Table 4. Initially 21 factors were used in the model and two were independently associated with 'any breastfeeding' rate at six months.
Table 3: Median breastfeeding (interquartile range) duration in (months) Han, Uygur and other ethnic groups in Xinjiang, PR China, 2003-2004

\begin{tabular}{ccccccccc}
\hline & \multicolumn{3}{c}{ Exclusive Breastfeeding } & \multicolumn{3}{c}{ Full Breastfeeding } \\
\hline Ethnic group & $\mathrm{N}$ & Median & $25 \%$ & $75 \%$ & 0.5 & $25 \%$ & $75 \%$ \\
\hline Uygur & 360 & 0.1 & 0.5 & 0.1 & 0.5 & 2.5 & 0.5 \\
Han & 578 & 1.5 & 3.5 & 0.5 & 3.5 & 4.5 & 0.5 \\
Others** & 281 & 2.5 & 6.0 & 0.5 & 4.5 & $*$ & 1.5 \\
\hline
\end{tabular}

* The duration could not be calculated because censored percentage of 'full breastfeeding' in Other Group is 34\% at six months ** The 'other ethnic groups $(\mathrm{n}=28 \mathrm{I})$ included Kazakh 199, Xibe 56 and 26 Hui babies.

\section{Discussion}

This is the first reported longitudinal study of breastfeeding in the Xinjiang province. The minority mothers include Kazakh, Hui and Xibe were more likely to breastfeed their babies than Han mothers. Their 'any breastfeeding', 'full breastfeeding' and 'exclusive breastfeeding' rates were higher and duration of 'exclusive breastfeeding' and 'full breastfeeding' were longer than Han ethnic group. The results are a little different with a survey in Karamay, a medium sized city in North Xinjiang, in 1999 [26]. In that retrospective study, 'exclusive breastfeeding' rate at four months was $64 \%$ in Han and 69\% in minorities (include Uygur, Kazakh and Mongolian) but the differences did not reach significant levels. The 'ever breastfed' rate in both Han and minority groups was $96 \%$. However the time (mean month) of introduction of solid foods was significantly later in minority group (six months) than Han (five months)[26].

Table 4: Factors Associated With the Risk Discontinuing 'Any Breastfeeding' to Six Months, Xinjiang, PR China, 2003-2004

\begin{tabular}{|c|c|c|c|c|c|}
\hline \multirow[t]{2}{*}{ Factors } & \multirow[t]{2}{*}{ Values } & \multicolumn{4}{|c|}{ Cox Regression } \\
\hline & & $\mathrm{n}$ & $\mathrm{HR}$ & & \\
\hline \multirow{3}{*}{ Ethnics } & Han & 40 & 1 & & \\
\hline & Uygur & 164 & 2.93 & 1.14 & 7.56 \\
\hline & Others & 63 & 0.94 & 0.31 & 2.88 \\
\hline \multirow[t]{3}{*}{ Age of Infant When Mother Returned to Work } & No Job & 77 & 1 & & \\
\hline & $>=6$ Months & 143 & 1.69 & 0.80 & 3.59 \\
\hline & $<6$ Months & 47 & 3.57 & 1.61 & 7.89 \\
\hline
\end{tabular}

$2 \log$ likelihood $($ deviance $)=630.94, \mathrm{df}=4$.

Non-significant variables were birth seasons, maternal age, job, years of education, delivery method, whether demand fed, time of making decision about infant feeding method, the time of baby's first suckling after birth, baby's first feed, how early breastmilk 'came in', whether maternal mother breastfed her babies, maternal mother's feeding preference, baby's gender, the gender mother prefer, baby's birthweight, mother's knowledge of formula, number of family members, whether pacifier used, whether mother able to breastfeed after returning to work.

All variables in the final model were variables for which, when excluded, the change in deviance compared with the corresponding chi-square test statistic on the relevant degrees of freedom was significant.

$\mathrm{HR}$ is Hazard Ratio and $95 \% \mathrm{Cl}$ is $95 \%$ confidence intervals. 
Uygur mothers were least likely to breastfeed their babies exclusively. This result was similar to the results from studies in Tibet, another minority area in West China, where the 'full breastfeeding' rate at the end of the first month was 56\% (both urban and rural areas) and in 4-6 months declined to $3.0 \%$ in urban areas and $12.8 \%$ in rural areas [12]. In the present study, the 'full breastfeeding' rates in Uygur babies were $47 \%$ at the first month, declining to $1 \%$ at six months. The traditional beliefs about breastfeeding of the minority mother's may be responsible for the low rate of exclusive breastfeeding. Many Uygur mothers would state: 'breastmilk was not thick enough for baby's growth' as the reason for the early introduction of solids. Tibetan mothers were also used to feeding babies water early because they want to follow their tradition feeding method [12]. However the early introducing of water or complementary foods may lead to shortening of breastfeeding duration and exposes the infant to increased rates of morbidity and mortality [27].

In this study, 'exclusive breastfeeding' and 'full breastfeeding' rates were low and their durations were short in all ethnic groups. They were well below Chinese and international targets $[8,28,29]$. Besides traditional inappropriate perceptions, the advertising and ready availability of infant formula could be factors in the early introduction of additional foods to some infants. This is reflected in the lower rates of 'exclusive breastfeeding' by mothers living in urban areas who enjoy higher incomes [12]. Inappropriate infant feeding advice given by health professionals was another factor influencing 'exclusive breastfeeding'. Many doctors thought that infant jaundice was associated with dehydration and so they suggested feeding water to babies they considered at risk. In reality an early first breastfeed and frequent breastfeeds with no restrictions help to prevent or reduce jaundice [30].

More mothers in 'other ethnic group' lived in rural areas and have lower income. The formula was not so easy to get for them as the mothers living in urban areas with more income. So 'any breastfeeding' and 'exclusive breastfeeding' rates were higher than Han and Uygur groups. Some studies showed that maternal smoking was negatively associated with breastfeeding duration [31-34]. In Xinjiang, the paternal smoking rate was $64.8 \%$ but only a few mothers smoke (1.7\%).

The main problem of breastfeeding in different ethnic groups in Xinjiang was the low prevalence of 'exclusive and full breastfeeding' rates. Mothers, especially Uygur mothers, need to be educated about the benefits of 'exclusive breastfeeding' for the first six months. However no specific factors, other than language, were identified to justify separate breastfeeding interventions specially targeted at Uygur or other minorities in Xinjiang. Further research, including qualitative studies are needed to provide a deeper understanding of the reasons for the early introduction of liquids and solid foods to infants who are being breastfed.

There are several limitations that need to be considered when interpreting the results of the study. As follow-up in this study was terminated at six months, the median duration of 'any breastfeeding' could not be determined. However the survival rates at six months still show the differences in ethnic groups. Further study is needed to identify factors associated with breastfeeding rate and duration in different ethnic groups. The proportion of mothers who could be contacted on follow up gradually declined over the duration of the project and at six months $79 \%$ of mothers provided information. The overall response in terms of person months in the study was $87.4 \%$ and these response rates need to considered when interpreting the study.

\section{Conclusion}

The breastfeeding rates on discharge from hospital in Xinjiang were $88.5 \%, 94.3 \%$ and $97.1 \%$ respectively, at six month $76.7 \%, 54.7 \%$ and $87.6 \%$ respectively. However, 'exclusive breastfeeding' rates in Han, Uygur and 'other minority' groups at discharge were $78.0 \%, 34.5 \%$ and $83.1 \%$ respectively, at six months $4.8 \%, 0.4 \%$ and 16.8 $\%$ respectively. Uygur babies were least likely to be 'exclusive breastfed'.

\section{Competing interests}

The author(s) declare that they have no competing interests.

\section{Authors' contributions}

FX: project design, data collection, data analysis and paper writing.

CWB: project design, data analysis and paper writing and revision.

GN: data collection and paper writing.

LS: data collection and paper writing.

YZ: data analysis.

AHL: data analysis.

\section{Acknowledgements}

We gratefully acknowledge the willing assistance given by the mothers in our study, the hospital staff and nursing students. Without this assistance the study would not have been possible. 


\section{References}

I. WHO Collaborative Study Team on the Role of Breastfeeding on the Prevention of Infant Mortality: Effect of breastfeeding on infant and child mortality due to infectious diseases in less developed countries: a pooled analysis. Lancet 2000, 355(February 5):45 I-455.

2. Binns CW, Lee M, Scott JA: The fetal origins of disease hypothesis: public health implications for the Asia-Pacific region. Asia Pac J Public Health 200I, I3(2):68-73.

3. WHO: Report of the expert consultation on the optimal duration of exclusive breastfeeding. World Health Organization 2001

4. Wang F, Zhu Z, Tong F: Discussion and suggestion about promoting national breastfeeding. China Maternal and Child Health Care 1991, 6(2):6-8

5. Chen j, Ji p: Process to promote breastfeeding in Beijing Maternal and Child Health Care of China 1993, 8(3):27.

6. Boaton VE, Gielen AC, Faden RR: Women intending to breastfeed: predictors of early infant feeding experiences. Am J Prev Med 1991:101.

7. Pang R: Baby friendly hospital improve breastfeeding. Maternal and Child Health Care of China 1993, 8(I):2-3.

8. Niu X, Zhao Y, liu Q: Education outline of Chinese Children's Development Plan in 1990's. Central Broadcadting and Television University Publication; 1993.

9. Zheng S: Initiate Baby Friendly Hospital, promote breastfeeding. Maternal and Child Health Care of China 1993, 8(2): 18-19.

10. Zhang H, Wan F, Pu C: Breastfeeding And Influence Factors In Wuhan Communities. Medicine And Society I 998, I I ( I 3):28-30.

II. Wenkun Z, Buo H, Linhong W: Breastfeeding in Beijing and Four Provinces in China. Chinese Journal of Health Education 2004, 20(I): 14-16.

12. Dang S, Yan H, Wang $X$, Zeng $\mathrm{L}$, Xie H: Breastfeeding survey in Tibet. Maternal and Child Health Care of China 200 I, I 6( I 2):744-747.

13. Simard I, O'Brien HT, Beaudoin A, Turcotte D, Damant D, Ferland S, Marcotte MJ, Jauvin N, Champoux L: Factors influencing the initiation and duration of breastfeeding among low-income women followed by the Canada prenatal nutrition program in 4 regions of quebec. J Hum Lact 2005, 2 I (3):327-337.

14. Dennis CL: Breastfeeding initiation and duration: a 1990-2000 literature review. I Obstet Gynecol Neonatal Nurs 2002 3 I(I): $12-32$

15. Celi AC, Rich-Edwards JW, Richardson MK, Kleinman KP, Gillman MW: Immigration, race/ethnicity, and social and economic factors as predictors of breastfeeding initiation. Arch Pediatr Adolesc Med 2005, I 59(3):255-260.

16. Xiao C: Breastfeeding in Shinezi. China Primary Health Care 1998:151-152.

17. Scott JA, Landers MC, Hughes RM, Binns CW: Factors associated with breastfeeding at discharge and duration of breastfeeding. J Paediatr Child Health 200I, 37(3):254-26I.

18. Scott JA, Aitkin I, Binns CW, Aroni RA: Factors associated with the duration of breastfeeding amongst women in Perth, Australia. Acta Paediatr 1999, 88(4):416-42I.

19. Duong DV, Binns CW, Lee AH: Breast-feeding initiation and exclusive breast-feeding in rural Vietnam. Public Health Nutr 2004, 7(6):795-799.

20. Li L, Zhang M, Scott JA, Binns CW: Factors associated with the initiation and duration of breastfeeding by Chinese mothers in Perth, Western Australia. I Hum Lact 2004, 20(2): 188-195.

21. Lakati A, Binns C, Stevenson M: The effect of work status on exclusive breastfeeding in Nairobi. Asia Pac J Public Health 2002, | 4(2):85-90.

22. Lakati A, Binns C, Stevenson M: Breast-feeding and the working mother in Nairobi. Public Health Nutr 2002, 5(6):7I5-7I 8.

23. Binns CW: Encourage and support breastfeeding. Journal of the Home Economics Institute of Australia 2004, I I (I):28-38.

24. Labbok M, Krasovec K: Toward consistency in breastfeeding definitions. Stud Fam Plann 1990, 2 I (4):226-230.

25. Binns CW, Scott J: Breastfeeding: reasons for starting, reasons for stopping and problems along the way. Breastfeed Rev 2002 I0(2):13-19.

26. $\mathrm{Yu} \mathrm{H}$, Song J: Breastfeeding among 368 infants in Karamay city, Xinjiang. Chinese Journal of Health Education 2000 I 6(1 0):581-583.
27. Riva E, Banderali G, Agostoni C, Silano M, Radaelli G, Giovannini M: Factors associated with initiation and duration of breastfeeding in Italy. Acta Paediatr 1999, 88(4):4 I I-4I 5.

28. Habicht JP: Expert consultation on the optimal duration of exclusive breastfeeding: the process, recommendations, and challenges for the future. Adv Exp Med Biol 2004, 554:79-87.

29. Kramer MS, Kakuma R: The optimal duration of exclusive breastfeeding: a systematic review. Adv Exp Med Biol 2004, 554:63-77.

30. NHMRC: Food for Health: Dietary Guidelines For Children And Adolescents In Australia. 2003

31. Scott JA, Binns CW: Factors associated with the initiation and duration of breastfeeding: a review of the literature. Breastfeed Rev 1999, 7(1):5-16.

32. Liu J, Rosenberg KD, Sandoval AP: Breastfeeding duration and perinatal cigarette smoking in a population-based cohort. Am J Public Health 2006, 96(2):309-3I4.

33. Amir LH, Donath SM: Does maternal smoking have a negative physiological effect on breastfeeding? The epidemiological evidence. Breastfeed Rev 2003, I I(2):19-29.

34. Horta BL, Victora CG, Menezes AM, Barros FC: Environmental tobacco smoke and breastfeeding duration. Am J Epidemiol I997, |46(2): |28-|33.

\section{Pre-publication history}

The pre-publication history for this paper can be accessed here:

http://www.biomedcentral.com/1471-2458/6/196/pre pub
Publish with Bio Med Central and every scientist can read your work free of charge

"BioMed Central will be the most significant development for disseminating the results of biomedical research in our lifetime. "

Sir Paul Nurse, Cancer Research UK

Your research papers will be:

- available free of charge to the entire biomedical community

- peer reviewed and published immediately upon acceptance

- cited in PubMed and archived on PubMed Central

- yours - you keep the copyright
BiolMedcentral 